\title{
Blood transfusions are associated with urinary biomarkers of kidney injury in cardiac surgery
}

\author{
Usman A. Khan, MD, ${ }^{a}$ Steven G. Coca, DO, MS, ${ }^{a}$ Kwangik Hong, MA, ${ }^{a}$ Jay L. Koyner, MD, ${ }^{b}$ \\ Amit X. Garg, MD, PhD, ${ }^{c}$ Cary S. Passik, MD, ${ }^{\text {,e }}$ Madhav Swaminathan, MD,${ }^{f}$ Susan Garwood, MD, ${ }^{g}$ \\ Uptal D. Patel, MD, ${ }^{\mathrm{h}}$ Sabet Hashim, MD, ${ }^{\mathrm{i}}$ Mackenzie A. Quantz, MD, ${ }^{\mathrm{j}}$ and Chirag R. Parikh, MD, PhD ${ }^{\mathrm{a}}$
}

Objective: Cardiac surgery is a major cause of acute kidney injury. In this setting, receipt of blood transfusions seems to be associated with a higher risk of acute kidney injury, as measured using serum creatinine values. We examined this association further by using urinary biomarkers of kidney injury.

\begin{abstract}
Methods: A total of 1210 adults underwent cardiac surgery and were divided into 3 groups on the basis of the receipt of intraoperative packed red blood cell units: no blood $(\mathrm{n}=894), 2$ or less packed red blood cell units $(\mathrm{n}=206)$, and more than 2 packed red blood cell units $(\mathrm{n}=110)$. Acute kidney injury was defined as $(1)$ doubling of serum creatinine from the preoperative value; (2) first postoperative urinary interleukin-18 in the fifth quintile; and (3) first postoperative urinary neutrophil gelatinase-associated lipocalin in the fifth quintile. We determined the relative risk for acute kidney injury outcome according to packed red blood cell units group after adjusting for 12 preoperative and surgical variables. By using the Sobel test for mediation analysis, we also evaluated the role of biomarkers in causing acute kidney injury through alternative pathways.
\end{abstract}

Results: Acute kidney injury was more common in those who received more than 2 packed red blood cell units. In patients receiving more than 2 packed red blood cell units, the adjusted relative risks were $2.3(95 \%$ confidence interval, 1.2-4.4, P.01), 1.36 (95\% confidence interval, 1.0-1.9, P.05), and 1.34 (95\% confidence interval, 1.0-1.8, $P .06)$ for doubling of serum creatinine, urinary interleukin-18 in the fifth quintile $(>60 \mathrm{pg} / \mathrm{mL})$, and urinary neutrophil gelatinase-associated lipocalin in the fifth quintile $(>102 \mathrm{ng} / \mathrm{mL})$, respectively. Furthermore, the effect of packed red blood cell units transfusion on acute kidney injury was partially mediated by interleukin- 18 .

Conclusions: Receipt of 2 or more packed red blood cell units during cardiac surgery is associated with a greater risk of acute kidney injury defined by serum creatinine and kidney injury biomarkers. (J Thorac Cardiovasc Surg 2014; 148:726-32)

Cardiac surgery is one of the leading contributors to acute kidney injury (AKI) in patients admitted to intensive

From the Section of Nephrology, ${ }^{a}$ Yale University School of Medicine, Veterans Affairs Medical Center, and the Program of Applied Translational Research, New Haven, Conn; Section of Nephrology, ${ }^{b}$ Department of Medicine, University of Chicago, Chicago, Ill; Division of Nephrology, ${ }^{\mathrm{c}}$ Department of Medicine, Western University, London, Ontario, Canada; Department of Cardiothoracic Surgery, ${ }^{\mathrm{d}}$ Danbury Hospital, Conn; University of Vermont College of Medicine, ${ }^{\mathrm{e}}$ Burlington, Vt; Division of Cardiothoracic Anesthesiology and Critical Care Medicine, ${ }^{f}$ Department of Anesthesiology, Duke University School of Medicine, Durham, NC; Department of Anesthesiology, ${ }^{\mathrm{g}}$ Yale University School of Medicine, New Haven, Conn; Division of Nephrology, ${ }^{\text {h }}$ Department of Medicine, Duke University School of Medicine, Durham, NC; Department of Surgery, ${ }^{i}$ Yale University School of Medicine, New Haven, Conn; and Division of Cardiac Surgery, ${ }^{\mathrm{j}}$ London Health Sciences Centre, London, Ontario, Canada.

The study was supported by National Institutes of Health Grant RO1HL085757 (C.R.P.) to study novel biomarkers of acute kidney injury in cardiac surgery.

Disclosures: Drs Parikh and Edelstein are named co-inventors on the IL-18 patent (no financial value). Dr Devarajan is the co-inventor on the NGAL patents. All other authors have nothing to disclose with regard to commercial support.

Received for publication Feb 25, 2013; revisions received Sept 11, 2013; accepted for publication Sept 25, 2013; available ahead of print May 10, 2014.

Address for reprints: Chirag R. Parikh, MD, PhD, Section of Nephrology, Yale University School of Medicine, 60 Temple St, Suite 6C, New Haven, CT 06510 (E-mail: chirag.parikh@yale.edu).

0022-5223/\$0.00

Published by Elsevier Inc. on behalf of The American Association for Thoracic Surgery

http://dx.doi.org/10.1016/j.jtcvs.2013.09.080 care. ${ }^{1-3}$ It is estimated that more than 1.25 million cardiac surgeries are performed annually worldwide. ${ }^{4}$ Given the large number of cardiothoracic surgeries and associated $\mathrm{AKI}$, it is necessary to understand potentially modifiable risk factors for cardiothoracic surgeries and associated AKI.

Acute blood loss or decrease in hematocrit (HCT) because of hemodilution is common in cardiac surgery; thus, blood transfusion is frequently performed during surgery to improve oxygen delivery to kidneys and other vital organs with the assumption that it will prevent ischemic injury. However, blood transfusion is not a benign intervention and has been shown to be associated with multiorgan failure, including AKI in patients undergoing cardiopulmonary bypass (CPB) ${ }^{5,6}$ Because blood transfusion is a potentially modifiable factor in cardiothoracic surgeries and associated AKI, the association between blood transfusion and outcomes in cardiac surgery has been widely investigated. More recently, data from a randomized controlled trial suggested that a restrictive protocol of blood transfusion was not inferior to a liberal protocol in patients undergoing cardiac surgery. ${ }^{7}$ To date, however, most studies investigating the relationship between blood transfusion and AKI have used creatinine or dialysis as measures of AKI. Serum creatinine is not 


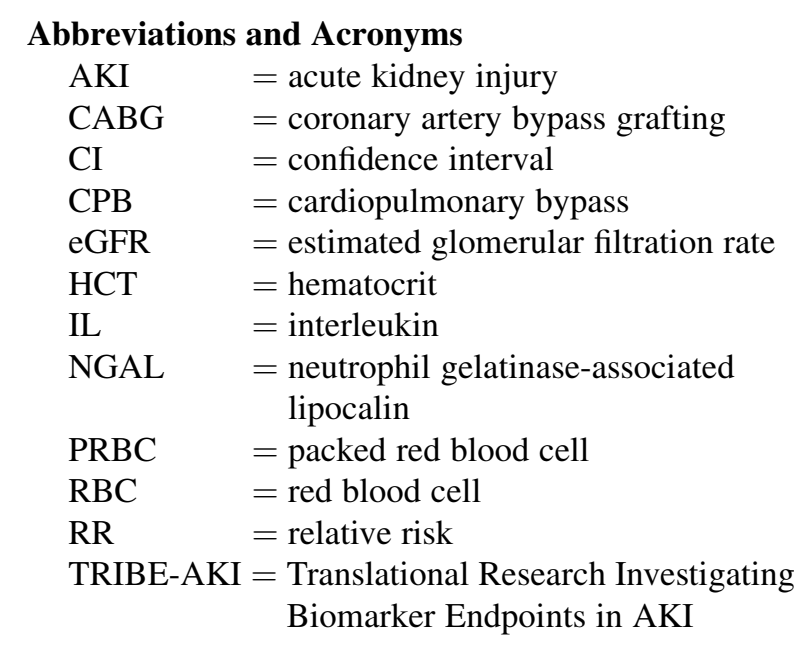

considered a robust marker for timely diagnosis in AKI because of the effect of several nonrenal factors, such as fluids, drugs, and muscle metabolism, on serum creatinine levels. In addition, creatinine is a functional marker of renal clearance rather than direct injury. However, there are some novel urine proteins, neutrophil gelatinase-associated lipocalin (NGAL) and interleukin (IL)-18, that are associated with ischemia reperfusion injury in the kidney and have demonstrated improved sensitivity for AKI diagnosis when compared with serum creatinine. ${ }^{8}$ In addition, animal studies have demonstrated that NGAL and IL-18 are not only early biomarkers but also mediators of AKI and contribute to apoptosis and necrosis of renal tubular cells. ${ }^{9}$ Because the association between packed red blood cell (PRBC) transfusion and AKI has been examined by using serum creatinine, the objective of the present study was to determine the degree of functional and structural injury associated with transfusion of PRBCs and to determine whether urinary biomarkers of kidney injury mediate clinical AKI in this setting.

\section{METHODS}

\section{Study Population}

We performed a prospective analysis of the adult patient population who underwent coronary artery bypass grafting (CABG) or valve surgery at 6 academic medical centers in North America between July 2007 and December 2009. All the patients eligible for the study consented to the Translational Research Investigating Biomarker Endpoints in AKI (TRIBE-AKI) protocol. ${ }^{10}$ The main inclusion criteria required cardiac surgery with high risk for AKI defined by the presence of 1 or more of the following: emergency surgery, preoperative serum creatinine greater than $2 \mathrm{mg} / \mathrm{dL}(>177 \mu \mathrm{mol} / \mathrm{L}$ ), ejection fraction less than $35 \%$ or grade 3 or 4 left ventricular dysfunction, age greater than 70 years, diabetes mellitus, concomitant $\mathrm{CABG}$ and valve surgery, or repeat revascularization surgery. ${ }^{10,11}$ The cohort included patients undergoing off-pump coronary artery bypass and patients undergoing CPB. Patients with evidence of AKI before surgery, prior kidney transplantation, preoperative serum creatinine level greater than $4.5 \mathrm{mg} / \mathrm{dL}$ ( $>398 \mu \mathrm{mol} / \mathrm{L})$, or end-stage renal disease were excluded.

\section{Sample Collection}

Urine and plasma specimens were collected preoperatively, and the first postoperative samples were collected soon after admission to the intensive care unit. The remaining daily blood and urine samples were obtained at the time of routine morning blood collection performed for clinical care. Serum creatinine values were recorded for every patient throughout the hospital stay. Further details on the sample collection and processing have been described. ${ }^{10,11}$

\section{Acute Kidney Injury Biomarker Measurements}

Urinary NGAL $(\mathrm{ng} / \mathrm{mL})$ and $\mathrm{IL}-18(\mathrm{pg} / \mathrm{mL})$ were measured with the ARCHITECT assay (Abbott Diagnostics, Abbott Park, Ill). Urine creatinine was measured by the modified Jaffe reaction. The intra-assay coefficient of variation for the urine creatinine assay was $5 \%$, whereas the coefficients of variations for the NGAL and IL-18 assays were approximately $5 \%$ and $8 \%$, respectively.

\section{Study Variables}

Published studies suggest a significantly increased risk of AKI with transfusion of more than 2 PRBC units. ${ }^{12-15}$ We therefore analyzed the cohort by dividing into 3 groups as receiving no blood, 2 or less PRBC units, and more than 2 PRBC units intraoperatively. The primary outcome was the development of AKI, defined in 3 ways: (1) at least a doubling in serum creatinine from the baseline preoperative value; (2) urinary IL-18 concentration in the highest quintile; or (3) urinary NGAL in the highest quintile. We limited our analysis to first postoperative biomarker values because we have previously shown the association of these values with AKI in cardiac surgery cases. ${ }^{10}$ Preoperative characteristics, operative details, and postoperative complications were collected. For postoperative complications, the definitions of the Society of Thoracic Surgeons database were used. The number of PRBC transfusions received intraoperatively was recorded for every patient. Cardiac catheterization if received within 48 hours of index surgery was recorded. Preoperative estimated glomerular filtration rate (eGFR) was estimated using the Chronic Kidney Disease Epidemiology Collaboration equations. ${ }^{16}$ All preoperative creatinine values were measured within 2 months before surgery.

\section{Statistical Analysis}

Patients' baseline characteristics were compared across the 3 groups. We analyzed categoric and continuous variables using chi-square and Kruskal-Wallis statistics, respectively. We assessed the outcome of severe AKI on the basis of serum creatinine and biomarkers as described earlier. We also examined the distribution of the urinary biomarkers across the 3 groups. We used the first postoperative values of urine biomarkers because these have been demonstrated to be associated with AKI in our prior observations. ${ }^{10,17}$ Relative risk (RR) of severe AKI was calculated using Poisson regression with robust error variance in the 2 groups who received 2 or less PRBC units or more than 2 PRBC units, using the group with no blood transfusion as reference. We adjusted for various important covariates that are associated with AKI, including patient demographics (white race, age, sex), clinical risk factors (preoperative eGFR, diabetes, hypertension, congestive heart failure, cardiac catheterization in the last 48 hours), and operative characteristics (elective vs nonelective surgery, $\mathrm{CPB}$ time and type of surgery [CABG, $\mathrm{CABG}$ and valve, valve]). To minimize the indication bias that is associated with PRBC use, we also used propensity scores as a covariate and weighted propensity scores to calculate the RR. The RR was adjusted for propensity score, which provides a way to summarize covariate information about group bias (treatment selection) into a scalar value. The propensity score probability was calculated from logistic regression after accounting for covariates listed earlier, including PRBC groups. 


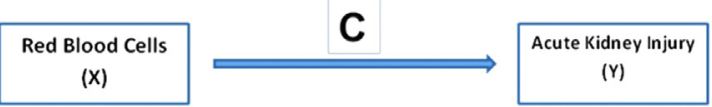

A

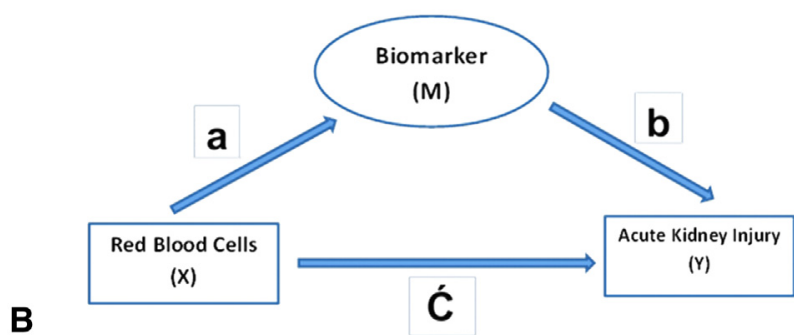

FIGURE 1. A, The direct effect of independent variable (X) on dependent variable (Y) denoted as C. B, The effect of $\mathrm{X}$ on $\mathrm{Y}$ through a mediator (M) where the association between $\mathrm{X}$ and $\mathrm{M}$ is denoted as " $\mathrm{a}$ ", the association between $\mathrm{M}$ and $\mathrm{Y}$ is denoted as " $\mathrm{b}$ ", and the association of $\mathrm{X}$ and $\mathrm{M}$ to $\mathrm{Y}$ is denoted as $\dot{C}$, such that $\mathrm{C}=\dot{\mathrm{C}}+\mathrm{ab}$.

To explore the association between blood transfusion and AKI further, we sought to analyze the alternative pathways that can mediate this effect. We conducted the mediation analysis to determine whether urine biomarkers are an intermediate between red blood cell (RBC) use and the development of AKI. To explore the mediation pathway, first the direct effect of independent variable $\mathrm{X}$ (PRBC) on dependent variable $\mathrm{Y}$ (AKI) was calculated as " $\mathrm{C}$ ". The association between $\mathrm{X}$ and $\mathrm{M}$ (biomarker) and $\mathrm{M}$ and Y were calculated as "a" and "b", respectively. Assuming there is mediation between $\mathrm{X}$ and $\mathrm{Y}$ through $\mathrm{M}$, the residual direct effect of $\mathrm{X}$ on $\mathrm{Y}$ was then calculated as "Ć" (Figure 1). The equation to calculate the effect of $\mathrm{X}$ on $\mathrm{Y}$ (ie, "C") then can be written as follows:

$$
\mathrm{C}=\mathrm{C}+\mathrm{ab}
$$

Provided "a", "b", and " $\mathrm{C}$ " remain significant, if Ć is nonzero but the direct effect of $\mathrm{X}$ to $\mathrm{Y}$ (ie, " $\mathrm{C}$ ") is decreased, then there is partial mediation through a mediator pathway. If $C$ is 0 (ie, the effect of $X$ to $Y$ disappears), then the effect is mediated fully through alternative pathway $\mathrm{M}$, which is a biomarker in this case. We used the Sobel test ${ }^{18}$ to evaluate the mediation analysis. The results were considered significant with a 2 -sided $\alpha$ error less than 0.05. All analyses were conducted in SAS version 9.2 (SAS Institute Inc, Cary, NC).

\section{RESULTS}

\section{Characteristics of the Study Cohort}

A total of 1210 patients were included in this analysis who underwent cardiac surgery in 6 university-affiliated hospitals in North America. A comparison of baseline characteristics between the patients who received no blood and the patients who received 2 or less PRBC units or more than 2 PRBC units is presented in Table 1 . The mean age of all patients was 71 years. Overall, $68 \%$ of the patients were male, $94 \%$ were white, and $42 \%$ had diabetes. A higher proportion of patients who underwent nonelective surgery or a combined procedure (CABG and valve) required more than 2 PRBC units. Also, more patients who underwent CABG with CPB required PRBC transfusion $(28 \%)$ as opposed to those who underwent off-pump coronary artery bypass $(15 \%)$. The mean eGFR was lower $(57.2$ $\mathrm{mL} / \mathrm{min} / 1.73 \mathrm{~m}^{2}$ ) in the patients requiring more than 2 PRBC units compared with those who did not require blood $\left(70.3 \mathrm{~mL} / \mathrm{min} / 1.73 \mathrm{~m}^{2}\right)$.

\section{Association of Packed Red Blood Cell Transfusion With Acute Kidney Injury}

The outcome of severe AKI defined by serum creatinine or novel biomarkers was higher in patients who received more than 2 PRBC units compared with those who did not receive any blood or received 2 or less PRBC units (Table 2). The first postoperative values of urinary IL-18 and urinary NGAL were significantly higher in patients who received more than 2 PRBC units compared with those who did not receive any blood or received 2 or less PRBC units (Figure 2).

In patients receiving more than $2 \mathrm{PRBC}$ units, the adjusted RRs were $2.3(95 \%$ confidence interval $[\mathrm{CI}], 1.2-4.4$; $P<.01), 1.36$ (95\% CI, 1.0-1.9; $P=.05)$, and $1.34(95 \%$ CI, $0.98-1.8, P=.06$ ) for doubling of serum creatinine, urinary IL-18 in the fifth quintile $(>60 \mathrm{pg} / \mathrm{mL})$, and urinary NGAL in the fifth quintile $(>102 \mathrm{ng} / \mathrm{mL})$, respectively (Table 2). The results for doubling of serum creatinine remained virtually unchanged when we adjusted for propensity score to receive PRBC (RR, 2.3; 95\% CI, 1.1-4.7).

\section{Mediation Analysis}

Mediation analysis revealed that $17 \%$ of the total effect of transfusing greater than 2 PRBC units on doubling of serum creatinine was mediated by IL-18. Mediation analysis for NGAL was not significant (Table 3).

\section{DISCUSSION}

The association between intraoperative blood transfusion during cardiac surgery and AKI using serum creatinine has been reported by prior studies. ${ }^{6,13-15,19}$ In our analyses, we demonstrated that compared with patients who received no or 2 or less units, receipt of more than 2 PRBC units was significantly associated with the risk for AKI, as defined not only by changes in serum creatinine but also by the absolute concentrations of urinary biomarkers of kidney injury (IL-18 and NGAL). This risk associated with greater than 2 units of blood was not attenuated in the propensity analysis models, which accounted for potential treatment selection bias. In concordance with the animal studies, we also demonstrated that some of the effect of clinical AKI is mediated through the IL-18 pathway.

The association between blood transfusion and AKI may be due to a direct transfusion-related kidney injury or an indirect effect in which the transfusion is acting as a surrogate marker for hypotension or decreased oxygen delivery. The pathophysiology of organ injury after blood transfusion is not clearly understood, but there are many possible mechanisms that likely play a role. It has been reported that RBCs 
TABLE 1. Baseline characteristics of patients by number of units transfused

\begin{tabular}{|c|c|c|c|c|c|}
\hline Characteristics & All patients $(\mathrm{n}=\mathbf{1 2 1 0})$ & No blood $(n=894)$ & 1-2 PRBC $(n=206)$ & $>2 \operatorname{PRBC}(\mathrm{n}=110)$ & $P$ value \\
\hline \multicolumn{6}{|l|}{ Preoperative factors } \\
\hline Age, y, mean (SD) & $71(10)$ & $71(10)$ & $73(11)$ & $73(11)$ & $<.0001$ \\
\hline Male, n (\%) & $820(86)$ & $682(76)$ & $93(45)$ & $45(41)$ & $<.0001$ \\
\hline White, n $(\%)$ & $1132(94)$ & $848(95)$ & $188(91)$ & $96(87)$ & .0032 \\
\hline Diabetes, $\mathrm{n}(\%)$ & $508(42)$ & $393(44)$ & $74(36)$ & $41(37)$ & .0626 \\
\hline Hypertension, $\mathrm{n}(\%)$ & $953(79)$ & $697(78 \%)$ & $165(80 \%)$ & $91(83 \%)$ & .45 \\
\hline Congestive heart failure, $\mathrm{n}(\%)$ & $312(26)$ & $195(22 \%)$ & $67(33 \%)$ & $50(45 \%)$ & $<.0001$ \\
\hline Cardiac catheterization in last $48 \mathrm{~h}, \mathrm{n}(\%)$ & $72(6)$ & $41(5 \%)$ & $22(11 \%)$ & $9(8 \%)$ & $<.01$ \\
\hline Myocardial infarction, $\mathrm{n}(\%)$ & $310(26)$ & $241(28 \%)$ & $47(24 \%)$ & $22(20 \%)$ & .15 \\
\hline Preoperative eGFR, mean (SD) & $68(21)$ & $70.33(20.04)$ & $66.05(21.98)$ & $57.18(21.65)$ & $<.0001$ \\
\hline Preoperative CKD stage & & & & & $<.0001$ \\
\hline Stage $1, \mathrm{n}(\%)$ & $164(14)$ & $131(15 \%)$ & $24(12)$ & $9(8)$ & \\
\hline Stage $2, \mathrm{n}(\%)$ & $612(51)$ & $478(53)$ & $99(48)$ & $35(32)$ & \\
\hline Stage $3, \mathrm{n}(\%)$ & $406(34)$ & $274(31)$ & $75(36)$ & $57(52)$ & \\
\hline Stage $4, \mathrm{n}(\%)$ & $28(2)$ & $11(1)$ & $8(4)$ & $9(8)$ & \\
\hline Preoperative sCr, mean (SD) & $1.09(0.34)$ & $1.08(0.32)$ & $1.07(0.36)$ & $1.23(0.45)$ & .0018 \\
\hline \multicolumn{6}{|l|}{ Preoperative medications } \\
\hline Aspirin & $894(74 \%)$ & $679(76 \%)$ & $134(65 \%)$ & $81(74 \%)$ & .0 \\
\hline Beta-blockers & $890(74 \%)$ & $665(75 \%)$ & $139(68 \%)$ & $86(79 \%)$ & .06 \\
\hline ACE inhibitors or ARB & $552(46 \%)$ & $415(47 \%)$ & $92(45 \%)$ & $45(41 \%)$ & .54 \\
\hline Statins & $894(74 \%)$ & $676(76 \%)$ & $143(69 \%)$ & $75(69 \%)$ & .07 \\
\hline Status of surgery & & & & & $<.0001$ \\
\hline Elective, n $(\%)$ & $956(79)$ & $738(83)$ & $150(73)$ & $68(62)$ & \\
\hline Nonelective, $\mathrm{n}(\%)$ & $254(21)$ & $156(17)$ & $56(27)$ & $42(38)$ & \\
\hline \multicolumn{6}{|l|}{ Intraoperative factors } \\
\hline OPCAB, n $(\%)$ & $117(10)$ & $100(11)$ & $14(7)$ & $3(3)$ & .01 \\
\hline $\mathrm{CPB}$ time, $(\mathrm{m})$ mean $(\mathrm{SD})$ & $114(60)$ & $106(55)$ & $125(60)$ & $160(73)$ & $<.0001$ \\
\hline Crossclamp time (min), mean (SD) & $78(44)$ & $72(41)$ & $85(47)$ & $108(52)$ & $<.0001$ \\
\hline Cardioplegia, n (\%) & $1068(88)$ & $779(87 \%)$ & $185(90 \%)$ & $104(95 \%)$ & .06 \\
\hline No. of PRBC units transfused, mean (SD) & $0.69(1.57)$ & $0(0)$ & $1.6(0.49)$ & $4.59(2.45)$ & $<.0001$ \\
\hline Type of surgery & & & & & $<.0001$ \\
\hline $\mathrm{CABG}, \mathrm{n}(\%)$ & $580(48)$ & $482(54)$ & $74(36)$ & $24(22)$ & \\
\hline CABG and valve, $\mathrm{n}(\%)$ & $277(23)$ & $176(20)$ & $54(26)$ & $47(43)$ & \\
\hline Valve, n $(\%)$ & $353(29)$ & $236(26)$ & $78(38)$ & $39(35)$ & \\
\hline Intra-aortic balloon pump, $\mathrm{n}(\%)$ & $56(3)$ & $31(3 \%)$ & $11(5 \%)$ & $14(13 \%)$ & $<.0001$ \\
\hline
\end{tabular}

Peak sCr is defined as the peak postoperative creatinine minus the preoperative serum creatinine value. $A C E$, Angiotensin-converting enzyme; $A R B$, angiotensin receptor blocker; $C A B G$, coronary artery bypass grafting; $C K D$, chronic kidney disease; $C P B$, cardiopulmonary bypass; $e G F R$, estimated glomerular filtration rate; $O P C A B$, off-pump coronary artery bypass; $P R B C$, packed red blood cell; $s C r$, serum creatinine; $S D$, standard deviation. $* P$ values were calculated using Kruskal-Wallis test for continuous variables and chisquare test for categoric variables.

preserved under hypothermic conditions undergo a series of changes that affect their viability and functionality post-transfusion. Stored RBCs become adenosine triphosphate and 2,3-diphosphoglycerate depleted, ${ }^{20}$ which causes cell membrane oxidative stress, resulting in cytoskeleton changes and decreased deformability. ${ }^{21-25}$ Current guidelines for blood preservation promote newer preservatives that can attenuate these metabolic effects, prolonging the stored time period to 42 days. However, these cell membrane processes are not completely halted. Berezina and colleagues ${ }^{22}$ concluded that stored RBCs can undergo significant irreversible changes and develop hemolysis during the second week of preservation long before the expiration currently set by blood banks. ${ }^{22}$ This finding has important clinical implications. In a study in which the complications after cardiac surgery were correlated with the age of stored blood, authors found that patients who received blood older than 14 days had a higher incidence of AKI $(2.7 \%$ vs $1.6 \%) .{ }^{19}$ Depletion of RBC 2,3-diphosphoglycerate also shifts the oxygen dissociation curve to the left, perpetuating ischemic injury. Increased platelet activation and thrombogenesis by altered cell membranes of stored RBCs also has been shown to be another possible mechanism of organ injury after blood transfusion. ${ }^{23}$ Hemolysis of stored blood also results in release of free hemoglobin and iron in the supernatant. ${ }^{24-26}$ Transfusion of 2 units of PRBC may result in elevation of free plasma hemoglobin by approximately 10 -fold above the normal limits. ${ }^{27}$ The free hemoglobin and iron can cause toxic injury to the tubules and lead to AKI. 
TABLE 2. Association of blood transfusion with acute kidney injury assessed with serum creatinine and urine biomarkers of kidney injury

\begin{tabular}{|c|c|c|c|c|c|c|c|c|c|}
\hline & \multicolumn{3}{|c|}{ Doubling of serum creatinine } & \multicolumn{3}{|c|}{ Urine IL-18 $>60 \mathrm{pg} / \mathrm{mL} \ddagger$} & \multicolumn{3}{|c|}{ Urine NGAL $>102 \mathrm{ng} / \mathrm{mL}_{\ddagger}$} \\
\hline & n $(\%)$ & $\begin{array}{c}\text { Unadjusted } \\
\text { RR }(\mathbf{9 5} \% \text { CI })\end{array}$ & $\begin{array}{c}\text { Adjusted RR } \dagger \\
\quad(\mathbf{9 5} \% \mathbf{C I})\end{array}$ & n $(\%)$ & $\begin{array}{c}\text { Unadjusted } \\
\text { RR }(95 \% \text { CI })\end{array}$ & $\begin{array}{c}\text { Adjusted RR } † \\
\quad(95 \% \text { CI })\end{array}$ & n $(\%)$ & $\begin{array}{c}\text { Unadjusted RR } \\
(\mathbf{9 5} \% \mathbf{C I})\end{array}$ & $\begin{array}{c}\text { Adjusted RR } \dagger \\
(\mathbf{9 5} \% \text { CI) } \\
\end{array}$ \\
\hline $\begin{array}{l}\text { No blood } \\
\qquad(\mathrm{n}=894)\end{array}$ & $30(3)$ & 1.0 (referent) & 1.0 (referent) & $150(17)$ & 1.0 (referent) & 1.0 (referent) & $146(16)$ & 1.0 (referent) & 1.0 (referent) \\
\hline $\begin{array}{l}1-2 \text { PRBC } \\
\quad(n=206)\end{array}$ & $9(4)$ & $1.30(0.63-2.7)$ & $1.06(0.52-2.2)$ & $44(22)$ & $1.30(0.96-1.75)$ & $1.02(0.75-1.39)$ & $44(22)$ & $1.33(0.99-1.8)$ & $0.98(0.72-1.34)$ \\
\hline$>2$ PRBC & $19(17)$ & $5.15(3-8.83)$ & $2.29(1.21-4.4)$ & $42(40)$ & $2.34(1.77-3.08)$ & $1.36(1-1.85)$ & $46(43)$ & $2.63(2.02-3.42)$ & $1.34(0.98-1.84)$ \\
\hline
\end{tabular}
$(\mathrm{n}=110)$

$P$ value* $<0001$

.01

.02

.05

.02

.06

$C I$, Confidence interval; $I L$, interleukin; $N G A L$, neutrophil gelatinase-associated lipocalin; $P R B C$, packed red blood cell; $R R$, relative risk. $* P$ values were calculated using chisquare test. $\nmid$ Adjusted for race, sex, age, preoperative eGFR, diabetes, hypertension, congestive heart failure, myocardial infarction, cardiac catheterization within 48 hours, status of surgery (elective vs nonelective), type of surgery (CABG, valve, or both), and perfusion time. $\ddagger \mathrm{IL}-18>60 \mathrm{pg} / \mathrm{mL}$ and NGAL $>102 \mathrm{ng} / \mathrm{mL}$ represent the fifth quintile of the first postoperative biomarker values in the cardiac surgery cohort.

It is possible that blood transfusion is simply a marker for higher-risk patients who are more susceptible to AKI because of low baseline HCT or a lower intraoperative HCT. Huybregts and colleagues ${ }^{13}$ analyzed the association of low HCT and PRBC transfusion with AKI using $N$-acetyl-ß-D-glucosaminidase as a marker of kidney injury. ${ }^{13}$ The authors found that the levels of $\mathrm{N}$-acetyl$B$-D-glucosaminidase were relatively higher among patients who had received 2 or more PRBC units when compared

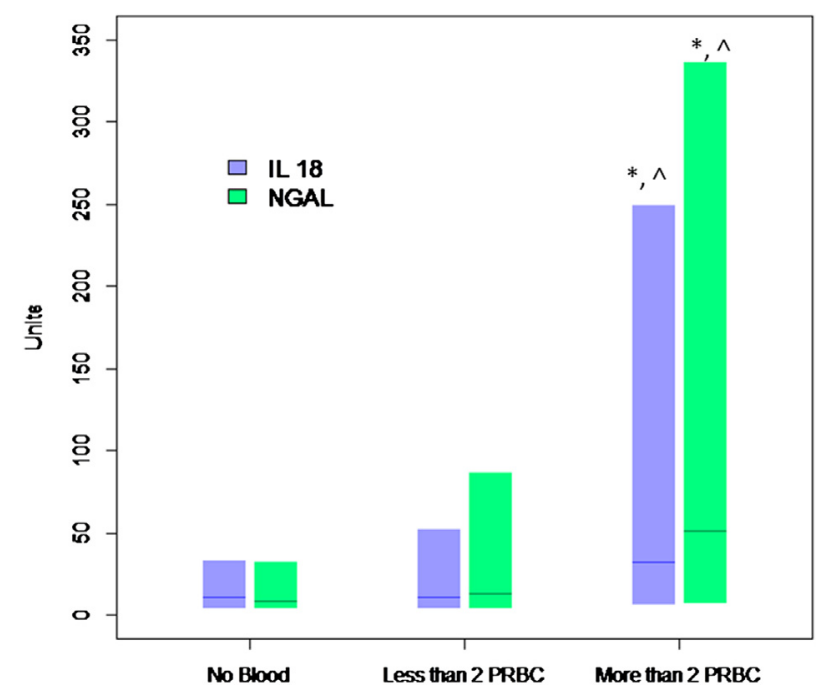

FIGURE 2. Distribution of urinary biomarkers in different groups by blood transfusion is shown in box plot. The bars represent the interquartile range, and the solid lines in the bars represent the median values of first postoperative urinary IL-18 and urinary NGAL. The median values of both urinary IL-18 and urinary NGAL were significantly elevated in those who received more than 2 PRBC units compared with those who received less than 2 PRBC units ( $P$ values for Wilcoxon test $<.0001$ and $<.0001$, respectively) or no blood ( $P$ values for Wilcoxon test $<.0001$ and $<.0001$, respectively). ${ }^{*}$ No blood versus more than 2 PRBC, $P<.0001$. ${ }^{\wedge}$ Less than 2 PRBC versus more than 2 PRBC, $P<.0001$. IL, Interleukin; $N G A L$, neutrophil gelatinase-associated lipocalin; $P R B C$, packed red blood cell. with the group with HCT less than $24 \%$, suggesting that transfusion of blood may have had some role in causing AKI in addition to low HCT. Other studies also have shown a synergistic effect of blood transfusion to perioperative anemia in increasing the risk of AKI while both factors were independently associated with AKI. ${ }^{24,28}$

It is noteworthy that we also did not observe an increase in risk of severe AKI with blood transfusion of up to 2 PRBC units. This observation has potentially important clinical implications. Tolerance of permissive anemia is important because perioperative blood conservation strategies are evolving and shown to be effective and associated with better outcomes. ${ }^{29,30}$ However, it is well known that excessively low HCT can be associated with postoperative AKI. ${ }^{31,32}$ Thus, our observations suggest that judicious transfusion of PRBC up to 2 units may be safe and prevent postoperative AKI. It is important to note that although poor organ perfusion is a cause of organ dysfunction in critically ill patients, HCT is a poor surrogate of oxygen delivery. The evidence is currently lacking that increasing HCT would necessarily lead to improved perfusion. ${ }^{33}$

Our examination of the expression of kidney injury biomarkers in response to blood transfusion is unique compared with previous data. IL-18 is a proinflammatory biomarker and causes increased apoptosis in the proximal tubular cells. IL-18 is activated from its pro-form by the caspase-1 pathway in response to several stressors, such as ischemia, nephrotoxins, or reperfusion. ${ }^{9}$ Moreover, IL-18 itself may be injurious to tissues and thus not only a biomarker but also a mediator of AKI through a caspase-1 and NLRP3 inflammasome-mediated apoptosis. ${ }^{9}$ Several studies in experimental animals have demonstrated that IL-18-neutralizing antibodies can reduce the amount of tissue injury. The mediation analysis we performed supports the notion that IL-18 expression may be exacerbating clinical AKI. Thus, this approach may be used as a model to identify other potential biomarker-modifiers, which may offer therapeutic targets to reduce AKI. 
TABLE 3. Mediation analysis to evaluate indirect effect of packed red blood cells on acute kidney injury via biomarkers

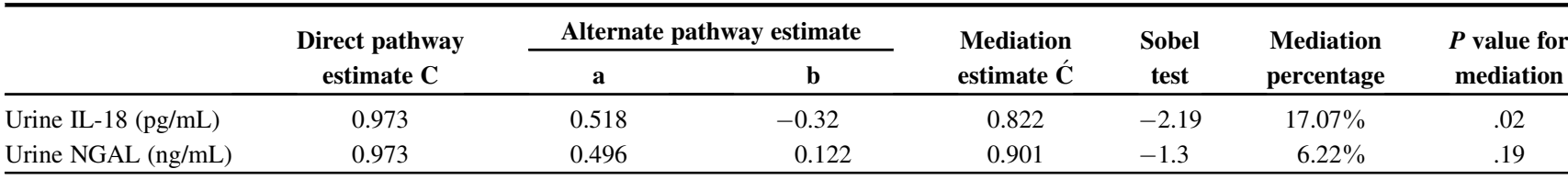

Mediation percentage is the percentage of total effect of PRBC transfusion on AKI that is mediated via biomarkers. $I L$, Interleukin; $N G A L$, neutrophil gelatinase-associated lipocalin.

\section{Study Limitations}

A major limitation in our study was that preoperative and perioperative HCT values were not collected in the original TRIBE-AKI protocol. However, prior studies have demonstrated that the lowest HCT during CPB is highly associated with peak fractional change in serum creatinine and the highest postoperative creatinine value. ${ }^{32}$ We also did not control transfusion triggers; we have simply reported the current intraoperative practices as they pertain to the institutions participating in this study. The dialysis events were low, and thus we could not study this group separately. This study also is observational in nature and thus limits our ability to confirm any potential causal association between PRBC and AKI outcomes. Although we attempted to account for differences in exposures, patients who required more PRBC transfusions may have had a greater severity of illness or intraoperative complications. We also did not collect the age of PRBC units transfused to our patients, which may affect the outcomes of AKI as discussed earlier.

\section{CONCLUSIONS}

Blood transfusion of more than 2 units is independently associated with AKI defined by both serum creatinine and urinary biomarkers of kidney injury in the setting of cardiac surgery. These findings provide additional evidence that may be used to design interventions that can alleviate kidney injury associated with blood transfusion. A major clinical implication of our study is that blood transfusion should be used judiciously in selected patients with a careful assessment of risk-benefit ratio.

Members of the TRIBE-AKI consortium: University of Chicago: Drs Jai Raman, Valluvan Jeevanandam, and Shahab Akhter; University of Cincinnati Children's: Dr Prasad Devarajan, Michael Bennett, PhD, Qing Ma, MD, and Rachel Griffiths; University of Colorado: Dr Charles Edelstein; London, Ontario: Dr Michael Chu, Dr Martin Goldbach, Dr Lin Ruo Guo, Dr Bob Kiaii, Dr Neil McKenzie, Dr Mary Lee Myers, Dr Richard Novick, Dr Mac Quantz, Virginia Schumann, and Laura Webster; Montreal Children's: Drs Michael Zappitelli and Ana Palijan; Yale-New Haven: Drs Michael Dewar, Umer Darr, John Elefteriades, and Arnar Geirsson.

\section{References}

1. Falvo A, Horst HM, Rubinfeld I, Blyden D, Brandt MM, Jordan J, et al. Acute renal failure in cardiothoracic surgery patients: what is the best definition of this common and potent predictor of increased morbidity and mortality. Am J Surg. 2008;196:379-83.

2. Kallel S, Triki Z, Abdenadher M, Frikha I, Jemel A, Karoui A. [Acute renal failure after cardiac surgery: evaluation of the RIFLE criteria.]. Nephrol Ther. 2013; 9:108-14.

3. Uchino S, Kellum JA, Bellomo R, Doig GS, Morimatsu H, Morgera S, et al Acute renal failure in critically ill patients: a multinational, multicenter study. JAMA. 2005;294:813-8.

4. Garg AX, Devereaux PJ, Yusuf S, Cuerden MS, Parikh CR, Coca SG, et al. Coronary Artery Bypass Grafting Surgery Off- or On-pump Revascularisation Study (CORONARY): kidney substudy analytic protocol of an international randomised controlled trial. BMJ Open. 2012;2:e001080.

5. De Santo L, Romano G, Della Corte A, de Simone V, Grimaldi F, Cotrufo M, et al. Preoperative anemia in patients undergoing coronary artery bypass grafting predicts acute kidney injury. J Thorac Cardiovasc Surg. 2009;138:965-70.

6. Habib RH, Zacharias A, Schwann TA, Riordan CJ, Engoren M, Durham SJ, et al. Role of hemodilutional anemia and transfusion during cardiopulmonary bypass in renal injury after coronary revascularization: implications on operative outcome. Crit Care Med. 2005;33:1749-56.

7. Hajjar LA, Vincent JL, Galas FR, Nakamura RE, Silva CM, Santos MH, et al. Transfusion requirements after cardiac surgery: the TRACS randomized controlled trial. JAMA. 2010;304:1559-67.

8. Haase-Fielitz A, Bellomo R, Devarajan P, Story D, Matalanis G, Dragun D, et al. Novel and conventional serum biomarkers predicting acute kidney injury in adult cardiac surgery-a prospective cohort study. Crit Care Med. 2009;37: 553-60.

9. Melnikov VY, Ecder T, Fantuzzi G, Siegmund B, Lucia MS, Dinarello CA, et al. Impaired IL-18 processing protects caspase-1-deficient mice from ischemic acute renal failure. J Clin Invest. 2001;107:1145-52.

10. Parikh CR, Coca SG, Thiessen-Philbrook H, Shlipak MG, Koyner JL, Wang Z, et al. Postoperative biomarkers predict acute kidney injury and poor outcomes after adult cardiac surgery. J Am Soc Nephrol. 2011;22:1748-57.

11. Shlipak MG, Coca SG, Wang Z, Devarajan P, Koyner JL, Patel UD, et al. Presurgical serum cystatin $\mathrm{C}$ and risk of acute kidney injury after cardiac surgery. Am J Kidney Dis. 2011;58:366-73.

12. Haase M, Bellomo R, Story D, Letis A, Klemz K, Matalanis G, et al. Effect of mean arterial pressure, haemoglobin and blood transfusion during cardiopulmonary bypass on post-operative acute kidney injury. Nephrol Dial Transplant. 2012;27:153-60.

13. Huybregts RA, de Vroege R, Jansen EK, van Schijndel AW, Christiaans HM, van Oeveren W. The association of hemodilution and transfusion of red blood cells with biochemical markers of splanchnic and renal injury during cardiopulmonary bypass. Anesth Analg. 2009;109:331-9.

14. Karkouti K, Wijeysundera DN, Yau TM, Callum JL, Cheng DC, Crowther M, et al. Acute kidney injury after cardiac surgery: focus on modifiable risk factors Circulation. 2009;119:495-502.

15. Karkouti K, Wijeysundera DN, Yau TM, McCluskey SA, Chan CT, Wong PY et al. Influence of erythrocyte transfusion on the risk of acute kidney injury after cardiac surgery differs in anemic and nonanemic patients. Anesthesiology. 2011; 115:523-30

16. Levey AS, Stevens LA, Schmid CH, Zhang YL, Castro AF III, Feldman HI, et al A new equation to estimate glomerular filtration rate. Ann Intern Med. 2009;150: 604-12.

17. Koyner JL, Garg AX, Coca SG, Sint K, Thiessen-Philbrook H, Patel UD, et al Biomarkers predict progression of acute kidney injury after cardiac surgery. J Am Soc Nephrol. 2012;23:905-14.

18. MacKinnon DP, Fairchild AJ, Fritz MS. Mediation analysis. Annu Rev Psychol. 2007;58:593-614.

19. Koch CG, Li L, Sessler DI, Figueroa P, Hoeltge GA, Mihaljevic T, et al. Duration of red-cell storage and complications after cardiac surgery. N Engl J Med. 2008; 358:1229-39. 
20. Scott KL, Lecak J, Acker JP. Biopreservation of red blood cells: past, present, and future. Transfus Med Rev. 2005;19:127-42.

21. Wolfe LC. Oxidative injuries to the red cell membrane during conventional blood preservation. Semin Hematol. 1989;26:307-12.

22. Berezina TL, Zaets SB, Morgan C, Spillert CR, Kamiyama M, Spolarics Z, et al. Influence of storage on red blood cell rheological properties. J Surg Res. 2002; 102:6-12.

23. Stadler I, Toumbis CA, Ambrus JL. Influence of cold storage altered red cell surface on the function of platelets. J Med. 1994;25:353-61.

24. Karkouti K. Transfusion and risk of acute kidney injury in cardiac surgery. $\mathrm{Br} J$ Anaesth. 2012;109(Suppl 1):i29-38.

25. Comporti M, Signorini C, Buonocore G, Ciccoli L. Iron release, oxidative stress and erythrocyte ageing. Free Radic Biol Med. 2002;32:568-76.

26. Donadee C, Raat NJ, Kanias T, Tejero J, Lee JS, Kelley EE, et al. Nitric oxide scavenging by red blood cell microparticles and cell-free hemoglobin as a mechanism for the red cell storage lesion. Circulation. 2011;124:465-76.

27. Vermeulen Windsant IC, Hanssen SJ, Buurman WA, Jacobs MJ. Cardiovascular surgery and organ damage: time to reconsider the role of hemolysis. J Thorac Cardiovasc Surg. 2011;142:1-11.
28. Loor G, Li L, Sabik JF III, Rajeswaran J, Blackstone EH, Koch CG. Nadir hematocrit during cardiopulmonary bypass: end-organ dysfunction and mortality. J Thorac Cardiovasc Surg. 2012;144:654-62.e4.

29. Moskowitz DM, McCullough JN, Shander A, Klein JJ, Bodian CA, Goldweit RS, et al. The impact of blood conservation on outcomes in cardiac surgery: is it safe and effective? Ann Thorac Surg. 2010;90:451-8.

30. Passik CS, Fernandes E, D'Amico A, Maldarelli W, Parikh C. Spare the blood, but save the kidneys. Ann Thorac Surg. 2011;91:2022-4.

31. Karkouti K, Beattie WS, Wijeysundera DN, Rao V, Chan C, Dattilo KM, et al. Hemodilution during cardiopulmonary bypass is an independent risk factor for acute renal failure in adult cardiac surgery. J Thorac Cardiovasc Surg. 2005; 129:391-400.

32. Swaminathan M, Phillips-Bute BG, Conlon PJ, Smith PK, Newman MF, Stafford-Smith M. The association of lowest hematocrit during cardiopulmonary bypass with acute renal injury after coronary artery bypass surgery. Ann Thorac Surg. 2003;76:784-92.

33. Ranucci M, Aronson S, Dietrich W, Dyke CM, Hofmann A, Karkouti K, et al. Patient blood management during cardiac surgery: do we have enough evidence for clinical practice? J Thorac Cardiovasc Surg. 2011;142:249, e1-32. 